\title{
Recreación como estrategia de integración social en un país en crisis. Prácticas de animación y recreación educativa en Uruguay (1955-1985)
}

\author{
Recreation as a strategy towards social integration \\ in a country in crisis. Educational animation and recreation practices \\ in Uruguay (1955-1985)
}

\section{Ricardo Lema Álvarez*}

\footnotetext{
* Doctor en Ocio y Desarrollo Humano (Universidad de Deusto, España). Docente e investigador en el Departamento de Educación (Universidad Católica del Uruguay).

* trlema@ucu.edu.uy https:/ / orcid.org/ 0000-00027745-6263
}

RECIBIDO: 3.9.2019

ACEPTADO: 5.11.2019

\section{Resumen}

El artículo presenta algunos hallazgos de la investigación de prácticas de recreación organizada en instituciones educativas de Uruguay, centrándose en el proceso histórico por el cual la recreación se desligó del ámbito de la educación física para constituirse en un perfil profesional propio. Partiendo del supuesto de que al promediar el siglo XX se produjo un quiebre con la matriz fundacional higienista y así la recreación comenzó a distanciarse del campo hegemónico de la educación física, se relevan, con un enfoque de estudios de la memoria, algunas experiencias clave para la introducción de una mirada sociocultural y educativa. El relevamiento se centró en fuentes secundarias (principalmente documentos y crónicas de época) que permitieron contextualizar el período reseñado, además de entrevistas a actores de ese período. Se concluye que estas experiencias definen una mirada propia y local de la recreación, orientada a la educación y la integración social.

Palabras clave: actividad de tiempo libre, educación extraescolar, historia de la educación, Uruguay. 


\begin{abstract}
The article presents some findings of research on organized recreation practices in educational institutions in Uruguay, focusing on the historical process by which recreation was separated from the field of physical education to become a professional profile of its own. Based on the assumption that halfway through the 20th century there was a break with the foundational hygienist matrix and thus recreation began to distance itself from the hegemonic field of physical education, some key experiences for the introduction of a sociocultural and educational perspective are highlighted with a focus on memory studies. The survey focused on secondary sources (mainly documents and chronicles of the time) which allowed contextualizing the period under review, in addition to interviews with actors from that period. The conclusion is that these experiences define a proper and local view of recreation, oriented to education and social integration.
\end{abstract} Keywords: leisure time activities, out of school education, educational history, Uruguay.

\title{
Introducción
}

Como sucedió en muchos países latinoamericanos, la etapa fundacional de la recreación organizada en el Uruguay estuvo caracterizada por la fuerte influencia del enfoque higienista promovido por la educación física, lo que se manifiesta a través de prácticas deportivas y de juego motor. El rol del Estado en la imposición de este modelo, a través de la Comisión Nacional de Educación Física (CNEF) y la influencia de la Asociación Cristiana de Jóvenes (ACJ-YMCA), es evidente (Dogliotti, 2012).

Durante esta primera mitad del siglo XX, la recreación se caracterizó por su enfoque higienista, subordinado al desarrollo de una educación física de inspiración anglosajona. Estas prácticas hegemónicas de recreación fueron impuestas desde el Estado, a través de la $\mathrm{CNEF}$, como producto de una explícita influencia del modelo deportivo norteamericano de la YMCA. Esta organización impuso, mediante la reformulación de las plazas de cultura física en plazas de deportes, un imaginario de prácticas recreativas orientadas al disciplinamiento de los cuerpos y el fortalecimiento de la raza, a través de juegos motores y actividad física al aire libre (Dogliotti, 2012; Lema, 2017).

En simultáneo a estas prácticas hegemónicas en el uso del tiempo libre, en este período también es posible reconocer, desde diversas formas de organización de la sociedad civil (asociaciones de inmigrantes, movimientos religiosos, comisiones barriales, etcétera) un conjunto de prácticas que plantearon miradas alternativas respecto al uso del tiempo libre y que integraron una dimensión más sociocultural. Esta ampliación de las prácticas recreativas, que incluyen no solo la dimensión física, sino también la 
cultural y social, tuvieron su desarrollo en nuevas experiencias de recreación organizada que cobraron protagonismo en la segunda mitad del siglo pasado, cuando la crisis económica y social generó un repliegue del Estado que permitió nuevos enfoques de la recreación.

\section{El enfoque de animación como respuesta a la crisis social}

En Uruguay, como en la mayoría de los países latinoamericanos, el enfoque higienista promovido por la educación física es el que monopolizó la recreación en la primera mitad del siglo XX, con la presencia hegemónica de las plazas de deporte en las prácticas sociales de recreación. Pero a partir de la década del cincuenta los cambios en el contexto nacional y mundial marcan un punto de inflexión en el desarrollo de la recreación, que comenzó a distanciarse de ese enfoque fundacional.

En la segunda mitad del siglo XX, cuando el país empezó a perder su fortaleza económica y la estabilidad social, las infraestructuras estatales que soportaban al modelo higienista comenzaron a caer. A ello se sumó la incapacidad del modelo para cubrir las nuevas necesidades e intereses de una sociedad que empezaba a perder su bienestar económico y social.

El año 1955 inició un proceso de deterioro del país, en primer lugar económico, luego social y político. La crisis económica sobrevino a partir de un prolongado estancamiento del agro, el agotamiento del modelo industrial de sustitución de importaciones y el auge de especulación financiera (Nahum, Frega, Maronna y Trochon, 1997). Esto repercutió negativamente en el bienestar de la población a través de la suba de precios, la inflación de la economía y la pérdida del salario real.

Se comenzó a generar un fuerte aumento del desempleo, mientras el Estado buscaba frenar este proceso incorporando mayor cantidad de empleo público, con lo que perdió, cada vez más, la posibilidad de sostenerse. La falta de empleo rural generó procesos de migración interna, del campo a la ciudad y de las ciudades a la capital, lo que formó cinturones de pobreza en la periferia (zona suburbana sin servicios básicos) y la ocupación de casas abandonadas en barrios céntricos.

Todos los índices económicos y sociales expuestos en este capítulo muestran cómo se fue desvaneciendo en estos años el Uruguay democrático, consensual, de clases medias satisfechas. El estancamiento económico, el empobrecimiento general de la población, el estallido de la violencia social, barrieron la imagen del país modelo, perdiéndose también la institucionalidad democrática a partir de 1973, como corolario del fin de una época. (Nahum et al., 1997, p. 157) 
El período reseñado, que va de 1955 a 1973, es comúnmente llamado el del Uruguay de la crisis y coincide con nuevos enfoques sobre el concepto de recreación, que comenzaron a disputar espacios hasta entonces monopolizados por el Estado. En este tiempo la recreación comenzó a desarrollar un nuevo enfoque, más acorde con la realidad social del país y con un papel menor del Estado, en el cual se reflejaron las influencias de los movimientos de animación europeos que empezaron a llegar a la región, una experiencia vinculada también a países en busca de salidas a la crisis generada por la Segunda Guerra Mundial.

Los nuevos paradigmas del ocio, formulados especialmente por los sociólogos franceses (Dumazedier, 1964), y el desarrollo europeo de modelos de animación social y cultural influyeron en la redefinición del modelo recreativo uruguayo hacia un perfil menos físico/ motor y más sociocultural. En esto cumplió su papel una nueva institución: la Asociación de Scouts Católicos del Uruguay (ASCU).

Si bien desde comienzos del siglo XX hubo en Uruguay grupos basados en la metodología scout, estos no lograron permanecer. Recién en 1947 se logró conformar una institución que reunió a la mayoría de los grupos existentes en el momento: la Asociación de Boy Scouts del Uruguay, que obtuvo el reconocimiento de la Organización Mundial del Movimiento Scout en 1950. Los grupos que integraron esta asociación se mantuvieron fieles a la metodología desarrollada por el fundador del movimiento, Baden Powell.

Sin embargo, en 1954 un grupo de scouts se escindió de esta asociación y formó la ASCU, bajo el liderazgo de Germán Sellera Gastambide. A la luz del progresismo católico de la década del sesenta (impulsado por el Concilio Vaticano II), los Scouts católicos comenzaron a generar una renovación pedagógica inspirada en los movimientos de animación franceses.

Francia concentró en ese momento la mayor asociación de scouts católicos y lideró la Conferencia Internacional de Scoutismo Católico, ya que el jefe de los Scouts de Francia, Michel Rigal, era a la vez secretario general de esta organización internacional. En un país donde la animación estaba captando los ámbitos educativos no formales, los scouts franceses de posguerra comenzaron a forjar su propio modelo scout. Este proceso se inició con la llegada de Rigal en 1952 a la Comisaría General Rover de los Scouts de France (el grupo más grande). Empezaron así una serie de transformaciones pedagógicas que pretendían volcar el movimiento a la sociedad de su tiempo. En lo metodológico, se modificó el sistema de patrullas creado por Baden Powell y se creó una nueva rama adaptada a los adolescentes de 15 a 17 años.

Los Scouts católicos de Francia establecieron una fuerte colaboración con sus homólogos uruguayos, tanto que Michel Rigal visitó Uruguay al menos dos veces, en 1960 y 1962 ("Noticias", 1962), con lo que se fortalecieron estos lazos y se sentaron las bases 
para un momento clave en la refundación del movimiento, que sería el viaje a Europa, en el verano austral 1964-1965.

Los viajes de verano eran una práctica recurrente en el estilo pedagógico impuesto por el fundador de la ASCU, Germán Sellera. Un grupo de 57 scouts viajó a Chile en 1957 y otro a Bariloche (sur de Argentina) en 1963. Estos viajes fueron una oportunidad de entrar en contacto con otras realidades scouts y con el revisionismo europeo, y especialmente de formar a los jóvenes mediante la convivencia.

En el verano 1964-1965 cerca de 94 jóvenes y adolescentes pertenecientes a la ASCU viajaron a Francia, donde tuvieron un primer contacto directo con sus homólogos franceses y con el enfoque de la animación que estos habían adoptado. Así lo cuenta el profesor Mario Bengoa, uno de los jóvenes que participaron:

El scoutismo francés viene con el viaje. [Sellera] hace el viaje llevando como scouts a jóvenes de 14 a 16 años, que son solo varones, con un grupo de «grandes» — algunos de entre 17 y 20 años-. Allá forman a los más grandes y a nosotros también, y volvemos. [...] Yo tengo toda la teoría de que Germán hace el viaje para refundar la asociación, y para hacerla con el modelo francés. (M. Bengoa, comunicación personal, 24 de octubre, 2014)

Si bien el viaje duró tres meses y medio, el contacto con los scouts de Francia fue breve. Tanto los jóvenes scouts como los educadores (que no tenían más de veinte años, en su mayoría) estuvieron entre siete y diez días en el campamento Jambville, a las afueras de París. El resto del viaje lo dedicaron a recorrer Europa, poniendo en práctica algunas de las estrategias pedagógicas centradas en la convivencia y el trabajo en proyectos.

Pese al breve contacto con los scouts franceses durante el viaje, la influencia fue importante. En ese momento los Scouts católicos de Francia estaban consolidando su propia renovación pedagógica y algunas de estas innovaciones se trajeron a Uruguay.

Llegamos e inmediatamente, al bajar al puerto, se fundan los Pioneros, que es la nueva etapa. Separa Scouts, que en Francia se llama Rangers - que es de 12 a 14y de 14 a 16 funda los Pioneros: trabajo en equipo, por proyectos, etc. [...] Los Pioneros son una invención francesa; los Scouts de Inglaterra, de Norteamérica y de los países de Latinoamérica bajo influencia norteamericana, y la Asociación Nacional [de Uruguay] siguen funcionando con la rama vieja. (M. Bengoa, comunicación personal, 24 de octubre, 2014)

En pocos años se dio un recambio generacional en la ASCU. Los que hicieron este viaje desplazaron a la mayoría de sus mayores y tomaron los principales cargos de dirección. Esto significó también un cambio ideológico, ya que la mayoría de los 
fundadores de la ASCU eran católicos conservadores y los nuevos referentes se identificaban más con el progresismo católico pujante en los años sesenta, fundamento de buena parte de los movimientos de animación franceses.

En el 68-69 la mayoría de todos esos [los adolescentes que participaron en el viaje] ya estamos siendo los educadores. En el verano de 1970 se hace el campamento nacional en laguna del Sauce y todos los que estábamos a cargo de los subcampos éramos nosotros. Todos teníamos 20, 21 y 22 años. Los que llevamos adelante el modelo francés fuimos nosotros, como primera generación de Pioneros y luego de educadores en el nuevo enfoque. Toda la parte social también sale de ahí; los que vivieron en La Frontera fueron al viaje a Europa. (M. Bengoa, comunicación personal, 24 de octubre, 2014)

La influencia francesa estuvo también mediada por el vínculo entre los scouts de Uruguay y de Chile, pues los franceses mantenían una influencia importante en ese país: «Los chilenos metieron un perfil más lúdico [que no tenían los franceses]; de ellos aprendimos danzas, canciones, grandes juegos con ambientación» (M. Bengoa, comunicación personal, 24 de octubre, 2014). La renovación pedagógica y metodológica en la Asociación fue posible gracias al protagonismo que adquirieron los más jóvenes y su contacto con otras realidades.

Este recambio generacional se dio en un contexto de crisis social y política muy fuerte, lo que en lo ideológico llevaba a asumir ciertas posturas que impactaron a su vez en el enfoque metodológico. Ya no se trataba de formar solamente a los jóvenes scouts, sino también de extender su labor en la sociedad, especialmente en los sectores más vulnerados por la crisis.

Tenemos como objetivo ayudar a las nuevas generaciones a decir sí a la vida, a integrarse a un mundo que está continuamente cambiando, a ser un elemento útil y transformador, luchando contra la resignación, a ser constructoras de la nueva sociedad, más justa y más humana, a vivir pensando en los otros, formando comunidades, a ser sensibles a las realidades que nos rodean, a tener un espíritu crítico y poder decidir LIBREMENTE con todos los elementos cómo resolver cada circunstancia de la vida, a crecer en la fe como se crece físicamente e intelectualmente. Tener estos objetivos no es exclusivo de los scouts, pero los scouts católicos del Uruguay se sienten llamados a construir con los otros un mundo nuevo y mejor transformándose en hombres nuevos. («Editorial», 1975, p. 11)

Esta postura llevó a los Scouts católicos a asumir compromisos en la transformación de la sociedad. En 1971 crearon el Hogar La Frontera, para atender a niños en 
situación de calle. Allí se encargaron de tareas productivas de granja (cría de cerdos, conejos, etcétera) y enseñar oficios. Grupos de la rama Rover (entre 17 y 19 años) dedicaban los fines de semana a campamentos de trabajo y a realizar actividades de animación y recreación con los niños (juegos, deportes, salidas, veladas, campamentos).

Esta dimensión de compromiso social se reforzó cuando 19 Rovers se establecieron en un predio lindero a La Frontera y decidieron asumir una experiencia de vida cristiana comunitaria denominada Comunidad El Rincón, para «vivir juntos, compartir la vida con los demás» (M. Bengoa, comunicación personal, 24 de octubre, 2014).

El crecimiento de los Scouts católicos se dio en la década del setenta, al tiempo que la crisis política del país alcanzaba un punto crítico con el quiebre institucional de 1973. Para ese entonces la ASCU era una de las organizaciones más importantes dentro de la Iglesia Católica, con una fuerte influencia en los grupos y movimientos juveniles y las instituciones educativas de esta confesión.

En virtud del papel jugado por los Scouts católicos y de la influencia francesa, el enfoque de la animación se implantó en Uruguay en un momento en que las necesidades sociales demandaban otro tipo de abordaje del uso del tiempo libre. Frente a la recreación higienista, sostenida mediante un modelo asistencialista con fuerte presencia estatal a través de las plazas de deporte, surgió un enfoque orientado al compromiso social, de la recreación como un medio de desarrollo y progresión personal, como estrategia de organización comunitaria y convivencia.

La recreación fue derivando así en prácticas de animación, con un mayor acento pedagógico y político, que en lo metodológico incorporaban el papel de los procesos grupales y técnicas de expresión y creación que trascienden el juego motor y deportivo, característico del enfoque higienista.

Si bien la experiencia de la ASCU es la que alcanzó mayor impacto, la influencia de los movimientos de animación y educación popular llegó no solo a los movimientos juveniles católicos, sino también a movimientos populares progresistas, e impactó incluso en instituciones tradicionales como la Asociación Cristiana de Jóvenes (ACJ-YMCA). En ese marco se inscribe la creación de un centro juvenil en Malvín, un barrio al este de Montevideo que estaba presentando signos de deterioro social y especialmente de delincuencia juvenil.

Por invitación de una directora de la escuela de la zona, se acercó a trabajar con los jóvenes el profesor Arnaldo Gomensoro: «Yo me negué a ir como psicólogo porque nunca me pareció interesante estudiar a la gente como se estudia a los monos: en una jaula. Y fui con una pelota y una red de vóleibol, a integrarme al grupo» (Gomensoro, 2004).

Así se inició una experiencia exitosa de recreación, que incorporaba campamentos y actividades deportivas con fines de reeducación juvenil. Desavenencias con el centro educativo llevaron a Gomensoro a abandonar la escuela y montar el club juvenil en el 
garaje de su propia casa: «Me fui y atrás mío se vino la mitad del grupo, al garaje de mi casa. Y creamos lo que llamamos El boliche de enfrente, un grupo al que llamamos Paideia - los pedagogos-. Eran más o menos 25 o 30 muchachos». (Gomensoro, 2004)

A partir de este grupo se formó el centro de barrio de la ACJ, que luego dio origen a la actual sede de Portones. El éxito de esta experiencia les facilitó el apoyo del municipio, el cual les cedió un terreno donde se montó un club juvenil que se constituyó en un factor de atracción para los jóvenes de la zona, con actividades deportivas, excursiones y campamentos, juegos de salón, música, biblioteca, trabajos manuales, entre otras actividades.

El modelo de club juvenil de barrio tomaba distancia de la matriz fundacional que la propia ACJ había introducido en el país. Ya no se trataba de formar jóvenes según los preceptos higienistas, sino de reeducar a jóvenes cuyo contexto social y económico los había llevado a situaciones de vandalismo y delincuencia (Gomensoro, 1954). En este modelo, la acción sobre el joven implicaba tanto la capacitación para el trabajo como la elevación de su nivel cultural, a fin de transformar su personalidad mediante la espiritualización de sus impulsos.

A diferencia del modelo de liderato de la ACJ, aquí el protagonista era el propio joven, coejecutor de la tarea educativa (Gomensoro, 1954). La importancia no radicaba en las actividades a desarrollar, sino en la relación educador-educando, un planteo que evidenciaba una influencia mayor del horizontalismo - que entonces promovían Paulo Freire y la educación popular latinoamericana- que del verticalismo del modelo de líder YMCA.

La recreación no se entendía como entretenimiento, sino como herramienta educativa: "Tomamos como base a la recreación como medio, el deporte como medio, el canoísmo, el montañismo, todo como medio. Y el fin era la educación o la re-educación" (Gomensoro, 2004).

En la pedagogía de pequeños grupos y al aire libre de Baden Powell, junto con la pedagogía de mando y los destacamentos de mando de Makarenko y el equilibrio en la relación educador-educando inspirada por Freire, están los fundamentos de los clubes juveniles dirigidos por Gomensoro.

Recreación formativa vs. entretenimiento. Y oblicuismo organizacional, en el sentido este que yo decía de Paulo Freire. Para nosotros el oblicuismo es la gran solución. Flexible según las circunstancias, con tendencia a llegar a la horizontalidad, siempre que se pueda, pero asumiendo la necesidad de verticalidad cuando también se impone. (Gomensoro, 2004)

En este enfoque sociocultural, la búsqueda de fundamentos propios de la pedagogía llevó a la recreación a incorporar muchas innovaciones pedagógicas, incluso antes 
que la enseñanza escolarizada. Y en un contexto de creciente ideologización se empezó a mezclar con las experiencias de educación popular que habían resurgido en Latinoamérica a partir de la pedagogía crítica.

En los años sesenta, en una etapa en la cual los conflictos ideológicos se agudizaron, el propio Gomensoro se volcó a promover las actividades recreativas en diversos sindicatos (Federación de la Carne, Sindicato de Cañeros, de la Fábrica Uruguaya de Neumáticos, de TEM) y, si bien se denominaron Centros de Educación Popular, las actividades recreativas y deportivas seguían siendo el centro de la estrategia de formación y organización comunitaria. «[...]el lema de estos centros era: despertar, unir y organizar. Despertar conciencia, unir para tomar fuerza y organizar para resultar eficientes» (Gomensoro, 2004). Fue una experiencia intensa, aunque duró pocos años. Con el aumento de la represión sindical, estos espacios de participación desaparecieron.

Tanto el revisionismo que se dio en los Scouts católicos como las propuestas recreativas que surgieron inspiradas por la educación popular configuraron un enfoque sociocultural de la recreación (Lema, 1999; Waichman, 2004). El énfasis comunitario y social que fue tomando la recreación en algunos ámbitos durante esta etapa llevó a priorizar las técnicas grupales y participativas y los juegos de expresión, en detrimento de los deportes y juegos físicos. En sintonía con el proyecto democratizador de la cultura, que está detrás del modelo de ocio de Dumazedier (1964), la recreación se concebía como un instrumento para llevar adelante la reeducación de las comunidades y la acción emancipadora.

Mientras el enfoque higienista se canalizaba a través del rol de profesor de Educación Física - hasta finales del siglo XX este fue el único rol profesional legitimado socialmente para llevar adelante los programas y actividades de recreación-, surgieron nuevos actores no profesionales que le disputaron ciertos espacios de recreación organizada y que expandieron esta nueva impronta sociocultural: entre otros, los animadores scout y los animadores pastorales, los educadores populares y un nuevo perfil de líderes ACJ (que algunos empezaron a denominar animadores comunitarios).

La interrupción democrática que se dio en Uruguay durante los años setenta y principios de los ochenta tendría una influencia decisiva en la evolución de la recreación. La dictadura militar, de ideología conservadora, redujo la acción comunitaria al prohibir el asociacionismo y proscribir a los movimientos de base marxista. Esto enlenteció el desarrollo del enfoque sociocultural y, paradójicamente, facilitó el surgimiento de un enfoque específicamente educativo, como veremos a continuación. 


\section{El enfoque educativo como respuesta a la crisis política}

La década del setenta del siglo pasado fue un período de fuerte represión política en Latinoamérica, y Uruguay no escapó a ese proceso. Como corolario del deterioro económico, social y político iniciado a mediados del siglo XX, en 1973 se inició en Uruguay un período de gobierno de facto y de gran represión social y política, a través de una dictadura cívico-militar de ideología conservadora.

En ese período fueron escasas las experiencias de asociacionismo popular, pero fue en estas excepciones donde persistió buena parte de la resistencia a la dictadura, y en muchos casos tuvo como protagonistas a experiencias de recreación organizada. Tal es el caso de la Federación Uruguaya de Cooperativas de Vivienda por Ayuda Mutua (FUCVAM) y la Asociación de Empleados Bancarios del Uruguay (AEBU), entre otras. Para este estudio es pertinente considerar la influencia de la ASCU y la ACJ, por la influencia que tuvieron en el desarrollo de la recreación en las instituciones educativas.

Entre los espacios de resistencia que se valieron de la recreación para escapar al férreo control policial y militar durante la dictadura se destaca el rol de muchos colegios privados, especialmente el de los colegios católicos inspirados por el progresismo de la Iglesia posconciliar. Los centros educativos fueron instituciones sujetas a un estricto control del régimen, pues se consideraba que estaban infiltrados por ideología marxista. Los contenidos estaban controlados; las actividades, vigiladas; los textos, filtrados por la censura, y los profesores, categorizados según su filiación ideológica.

En este contexto de control sobre la enseñanza, las instituciones debían ingeniárselas para llevar adelante una propuesta educativa propia. Por esta razón, muchas de ellas - principalmente colegios católicos- comenzaron a explorar propuestas alternativas durante el tiempo libre extraescolar, que les permitieran a su vez emplear a los maestros y profesores destituidos por el gobierno, impedidos de ingresar a las aulas.

Las actividades recreativas permitieron a estas instituciones llevar adelante una educación más abierta y dar oportunidades de empleo a muchos docentes proscriptos. Por otra parte, el prestigio alcanzado por los Scouts católicos llevó a incorporar muchos educadores para llevar adelante tareas de animación y coordinación de los grupos liceales.

Los lugares donde entraron muchos son el Zorrilla [colegio y liceo de los Hermanos Maristas], el San Juan Bautista [colegio de los Hermanos de la Sagrada Familia] y el Seminario [Colegio Sagrado Corazón, de la Compañía de Jesús], en distintos cargos. Los Scouts eran muy valorados durante todo ese período de dictadura por la Iglesia. [...] Cuando llegamos nosotros a los Maristas, los campamentos existían. 
Pero nosotros incorporamos las caminatas, los campamentos de trabajo al Campo Escuela. (M. Bengoa, comunicación personal, 24 de octubre, 2014)

Se generó así una migración de la recreación desde los ámbitos de educación no formal, muchos de los cuales empezaban a ser prohibidos, hacia ámbitos de educación formal. Con este impulso se desarrollaron, al margen de la propuesta curricular de la educación física, actividades lúdicas y campamentiles en muchos colegios católicos (Maristas de Punta Carretas, San Francisco de Asís, Pedro Poveda, San Juan Bautista, Sagrado Corazón, Sagrada Familia, Juan XXIII, etcétera), pero también en colegios metodistas (Instituto Crandon) e incluso laicos (John F. Kennedy). En muchos de estos centros se dio una síntesis de tradiciones, especialmente la recreación de la ACJ con la animación de los Scouts, que dio pie a un nuevo enfoque de la recreación en instituciones educativas.

Fuimos construyendo, había gente scout con ese [mismo interés] [...]. Yo agradezco, aprendí muchas cosas de los Scouts, de ese modelo, de los viejos compañeros y de los actuales también. [...] Y se generó un modelo [propio] que yo creo, sin vanagloriarlo, que se ha ido tomando en otros colegios. De hecho, fichas [clases sistematizadas] que usábamos acá o cosas que aparecen [en otros Colegios], donde se ve que el curso es muy similar en la estructura, en algunos componentes, y se ha ido generando desde ese colectivo [tradición ACJ y tradición Scout], más el aporte creo sustantivo de los hermanos, que le daban esa línea de pensamiento marista de alguna manera. (L. Machado, comunicación personal, 20 de marzo, 2015).

De esta forma se introdujo un enfoque de animación en muchos de estos colegios. La recreación se desarrolló en estas instituciones educativas no tanto desde el rol del profesor de educación física, sino mucho más desde estos roles de educadores formados, muchos de ellos, en ámbitos de animación scout. Esto llevó a que el enfoque higienista tuviera un impacto reducido en los ámbitos educativos. En cambio, el enfoque sociocultural, luego devenido en enfoque educativo, fue el que realmente tuvo su desarrollo en las instituciones privadas.

Por otra parte, la dictadura marcó un punto de inflexión en el vínculo entre educación física y recreación. El concepto de recreación se vio interpelado por una mirada crítica de la pedagogía, al tiempo que se integraron nuevos enfoques provenientes de la educación popular y la expresión corporal. A este proceso contribuyeron las experiencias de resistencia que se dieron dentro de la ACJ y en particular la experiencia de la unidad Apex, donde se concentró un grupo de estudiantes de Educación Física en busca de alternativas a su formación. 
Si bien la mayoría de los centros de barrio populares habían sido prohibidos, hubo algunas excepciones. Entre estas, la unidad Apex de la ACJ fue otro de los ámbitos de resistencia. La ACJ, por su perfil humanista, era considerada un lugar de referencia para quienes resistían a la dictadura. En parte en su sede central, pero principalmente en las unidades barriales, se fueron constituyendo espacios de concientización y lucha. Ese fue el caso de Apex, ubicado en un barrio de clase media (Unión), que era una extensión del Departamento de Obra Comunal.

Apex tenía un funcionamiento bastante particular, con autonomía respecto a la institución central y con predominio de líderes identificados con un pensamiento progresista de izquierda:

Se convirtió eso en un centro de resistencia, de hacer cosas con la gente, cosas que no se podían. También de dar línea, línea ideológica. Allí fue donde empecé a escuchar [...] hablar del hombre nuevo; nunca había escuchado. (L. Machado, comunicación personal, 20 de marzo, 2015)

Allí se formó gente muy militante, luego referentes de organizaciones sociales y políticas. En esa época la dirección de la Unidad estuvo a cargo de José Pedro Perdomo, quien le dio una impronta ideológica particular e impulsó la formación de líderes con un perfil de militancia:

El discurso [de Perdomo] era crear conciencia crítica, pensar gente para el cambio. [Los líderes] reflexionábamos, muy desde las dinámicas, las técnicas grupales. [...] Era un grupo crítico, hacíamos dinámicas de grupo, [...] tratábamos de hacer cosas que en otro lado no se hacían. (L. Machado, comunicación personal, 20 de marzo, 2015)

En un proceso similar al que había vivido la Asociación de Scouts Católicos del Uruguay unos años atrás, Perdomo desplazó a los dirigentes mayores para dar entrada a una generación de jóvenes líderes, muchos de ellos estudiantes de Educación Física, pero con una mirada crítica de la educación:

Fuimos formando un grupo interesante de profesores. Profesores [de Educación Física], pero no era que fuéramos a dar clases de educación física; éramos profesores, pero había otras cosas mucho más interesantes que la clase de educación física de un club. (L. Machado, comunicación personal, 20 de marzo, 2015)

En ese momento, el Instituto Superior de Educación Física (ISEF) estaba intervenido por los militares - al igual que el resto de las instituciones de educación pública- 
y el plan de formación se orientaba a la gimnasia y el deporte con perfil conservador. Para los jóvenes interesados en la recreación, este era el único ámbito de formación profesional, y varios líderes de la ACJ optaron por ella.

Nuestra generación es una generación que zafó de la dictadura. [...] No estuvimos en esa generación anterior [que sufrió la violencia del Estado] por un par de años. Y esa generación es la generación que quedó fuera, pero queriendo hacer cosas. (L. Machado, comunicación personal, 20 de marzo, 2015)

En ese contexto de represión, muchos estudiantes demandaban un espacio alternativo de reflexión sobre el papel de la educación física en la sociedad.

Estando en tercero decimos: «Tenemos que hacer algo con los estudiantes nuevos». Sabíamos que había profesores proscriptos, que no podían dar clases. Hagamos cursos u otras cuestiones para esta gente. Pero el tema es que no podíamos hacer un contracurso por ahí, era riesgoso, realmente juntarte era riesgoso. Entonces inventamos un equipo de fútbol. «Hagamos un equipo de fútbol que juegue en la Liga Universitaria, y bajo la sede del equipo de fútbol podemos juntarnos». (L. Machado, comunicación personal, 20 de marzo, 2015)

Con el pretexto de conformar un equipo de fútbol, se agruparon bajo el nombre Barbas y se inscribieron en la Liga Universitaria de Deportes. La experiencia deportiva fue muy significativa, pues introdujeron una perspectiva lúdica del deporte en un contexto que, aunque amateur, era de alta competencia.

Los viernes por la noche se reunían en la unidad Apex de la ACJ, supuestamente para preparar los partidos del fin de semana. Sin embargo, esa era la fachada ante los ojos de los militares, pues en realidad las reuniones de los viernes fueron un espacio de reflexión, intercambio y formación paralela a la enseñanza de la educación física militarizada en el ISEF.

Lo que menos hablábamos era de fútbol. [...] Traíamos gente, profesores proscriptos la mayoría de ellos, alguien que se animaba y lo traíamos para una charla. Estudiábamos de otros profesores, como por ejemplo Mariano Giraldes, que estaba de onda en ese momento. Lo estudiábamos, investigábamos y hacíamos un taller sobre lo que el tipo proponía. Y también cosas nuestras, no solo de educación física. Me acuerdo de haber tenido talleres - era bastante revolucionario para la época- de discapacidad, de género, cosas que en aquel momento a nadie se le ocurría plantearse. Era como un instituto - capaz que suena muy ambicioso- paralelo para alguna gente. (L. Machado, comunicación personal, 20 de marzo, 2015) 
Aquel contracurso se caracterizaba por su heterogeneidad. No preexistía una teoría educativa que alineara los enfoques, sino que esta se fue construyendo a partir de aportes diversos que incluso trascendían la educación física, ya que pronto se integraron compañeros de otros ámbitos (estudiantes de Bellas Artes, educadores populares, etcétera), que, aunque no compartieran la profesión, compartían la ideología:

Y ahí empezó a venir gente de otros lados, sobre todo con la murga. En aquella época tenía que ser gente muy de confianza, amigos, gente que no era de educación física, pero que teníamos una ideología común. [...] Eran formas de militancia, también, y relativamente de encontrarles respuestas a algunas cosas. (L. Machado, comunicación personal, 20 de marzo, 2015)

El Barbas se convirtió en poco tiempo en un espacio de resistencia y de transformación del campo de la educación física y la recreación. Muchos jóvenes llegaron allí buscando un espacio donde reflexionar libremente sobre el rol profesional y adquirir herramientas de intervención educativa que trascendieran el enfoque tecnicista del ISEF.

Yo empecé las clases un lunes, y los martes de noche ya venía al Barbas, el lunes tenía que estar en el ISEF y el martes de noche tenía que estar en el Barbas. Fue así: «Vos si vas a ser profe de educación física tenés que ir el martes a tal hora; a las siete de la tarde se reúne el Barbas y ahí vas a ser profesor de educación física». Es más, podías faltar al ISEF, pero ahí no podías faltar. Y bueno, fue así, desde el primer año me vinculé al Barbas y prácticamente fui haciendo una carrera paralela en el instituto, más vinculada al movimiento, la motricidad, y en el Barbas las cuestiones de peso político, relacionadas con la educación. En el Barbas tuve el curso de Educación Popular en el año 82, cuando todo tenía que ser medio subterráneo, porque aparecía la palabra popular e ibas preso. (E. Cal, comunicación personal, 1 de junio, 2015).

A partir de este espacio se fue construyendo una mirada de la educación física, entendida como una práctica social que trascendía lo corporal, con una finalidad de cambio y transformación social que denotaba la influencia de los movimientos de animación y de educación popular. Se integraban prácticas que iban más allá del deporte y la actividad física: prácticas recreativas, lúdicas, musicales, artísticas, etcétera.

Después del Barbas salió la murga del Barbas, que fue una de las primeras murgas estudiantiles. [...] Actuamos bastante con la murga del Barbas; el primer cuplé se llamaba «Educando» y hablaba de la educación. La historia de un niño que va creciendo. [...] La murga surgió como una forma de expresión popular y de decir 
algunas cosas hacia afuera, no quedarnos ahí adentro. (L. Machado, comunicación personal, 20 de marzo, 2015)

Desde este espacio se generaron también actividades de extensión, con un fuerte sentido de militancia social y política. Por ejemplo, recibieron a los hijos de exiliados que venían de visita a Uruguay y realizaron actividades recreativas para ellos.

La recreación era totalmente instrumentalista en ese momento. Recreación para formar cabezas. Había una carga ideológica muy fuerte en ese encuentro, [pero] los pibes venían para pasarla bien. (L. Machado, comunicación personal, 20 de marzo, 2015)

La experiencia del Barbas se constituyó en un ámbito de resistencia a la dictadura, pero también de ruptura con la tradición de la educación física. Muchos de los profesores que pasaron por este proceso contribuyeron a renovar la mirada de la recreación incorporando el arte y la lúdica, además de una dimensión pedagógica crítica que se desarrolló en los años de posdictadura.

Es difícil determinar las diversas influencias en un grupo heterogéneo, pero muchas de estas influencias trascendían el ámbito de la educación física. Luis Machado, uno de los referentes del Barbas, destaca tres influencias en ese momento: los cursos de recreación que el profesor argentino Juan Carlos Cutrera dictara en el ISEF en los años setenta, la influencia del profesor uruguayo radicado en Alemania José Posada, y los cursos del profesor mexicano Carlos Núñez, referente de la educación popular.

Yo fui antes de ser estudiante. Me colé en un curso de Cutrera y me enamoré del tipo y de la recreación. [...]Y hay cosas que sigo haciendo que aprendí en ese curso. Esa misma cuestión la llevé en algún momento al Barbas y yo hice algunos cursos de recreación basados en eso. [...] Otro tipo que nos influyó fue José Posada [...] desde lo corporal, también era una revolución, nosotros veníamos de la educación física y los profes que teníamos eran de un paradigma del cuerpo muy particular. Y este tipo trabajaba desde el ritmo, desde la creatividad, fluía de una manera que era increíble y pila de cosas que tomamos de este hombre, José, y que de alguna manera ha ido permeando [...] desde una afectividad, una carga, de cambiarte la forma de ver el mundo muy fuerte. [...]Y otro tipo que nos influyó muchísimo [fue] Carlos Núñez. [...] Estuvimos con Ariel en ese curso y nos dio vuelta la cabeza. Dinámicas de grupo, de conciencia crítica, todos esos juegos centroamericanos que están en estos libros [...] Eran técnicas participativas para la educación popular; era educación a partir de técnicas, educar para un cambio, para la conciencia, para 
fortalecer las comunidades. [...] Y con todo eso nosotros fuimos armando una mélange de cosas. (L. Machado, comunicación personal, 20 de marzo, 2015)

Motivados por el espíritu renovador del Barbas, muchos profesores incorporaron a la recreación técnicas lúdicas, que no se redujeron al juego motor, y técnicas para la conducción grupal - Cutrera-, recursos de la expresión y creación corporal y sonora - Posada-, además de técnicas de dinamización de procesos grupales emancipatorios - Núñez-. Experiencias como las del Barbas configuraron un nuevo perfil del recreador, entendido como un militante educativo.

Y realmente nuestro espacio era - yo siempre la llamo así- una militancia educativa, y yo me defino así hoy por hoy. Soy militante desde la educación y voy a formar conciencia crítica y sigo haciéndolo ahora. Valores, justicia, pero desde lo que yo sé hacer, desde lo educativo y demás. (L. Machado, comunicación personal, 20 de marzo, 2015)

La experiencia del Barbas fue muy intensa, aunque su presencia duró unos pocos años. Este espacio se fue agotando en los últimos años de la dictadura, cuando comenzaron a surgir otros ámbitos de participación política y sindical a recuperar, que llevaron la militancia hacia los ámbitos sindicales y políticos.

Ahí fue como el fin del Barbas, pues se empezaban a abrir espacios que había que recuperar. Nos metimos con fuerza en el gremio de educación física, en la ACJ también había uno y nos metimos con varios compañeros, y tratamos de hacer las cosas a nuestra manera, de llevar el modelo del Barbas, participativo, democrático [...] pero en algún momento empezaron a venir los viejos militantes y empezaron a decir «esto se vota, se vota [...]». (L. Machado, comunicación personal, 20 de marzo, 2015)

La experiencia del Barbas fue breve y el grupo se disolvió al finalizar la dictadura. Sin embargo, tendrían un impacto significativo, no solo en la renovación pedagógica de la educación física, sino también en el desarrollo del campo de la recreación más allá de los límites de la educación física. A partir de este grupo se desarrollaron varias experiencias desde los años noventa: como el Campamento El Quijote primero, el Campamento y Centro de Capacitación La Mancha después, la Bienal del Juego... Varios de sus protagonistas se insertaron, a su vez, en instituciones educativas y comunitarias, donde expandieron el enfoque y aumentaron su profesionalización.

Yo creo que sí, que impregnamos a algunas generaciones.Y muchos nos dedicamos a eso después. Yo después entré en el ISEF y de alguna manera seguí haciendo esa 
militancia educativa. Educábamos en recreación, pero educábamos para la vida, para transformar, para ser multiplicadores de un mundo mejor. (L. Machado, comunicación personal, 20 de marzo, 2015)

A partir de estos ejemplos de organizaciones que incorporaron la recreación en su resistencia a la represión militar, hemos intentado justificar una transformación que se genera en las formas de entender estas prácticas. La educación física perdió así la hegemonía sobre el campo de la recreación, al tiempo que las prácticas recreativas se incorporaron a las instituciones educativas. Desde estas instituciones la recreación asumió un enfoque educativo que puso en el horizonte la formación integral del sujeto, para lo cual incorporó técnicas lúdicas, de expresión y creación, y de intervención en los procesos grupales, al tiempo que construyó un marco teórico de reflexión sobre el campo, con una mirada crítica de la pedagogía.

El retorno a la democracia, a partir de 1985, facilitó la expansión de la recreación en las instituciones de educación formal. En numerosos colegios se desarrollaron programas recreativos, campamentos, convivencias, etcétera, como complemento de la formación integral de niños y jóvenes (Lema, 2016a). La participación aumentó y comenzó a darse un fenómeno nuevo: los cursos de líderes, animadores y recreadores dentro de las instituciones (Lema, 2016b).

\section{Conclusiones}

La influencia de un enfoque sociocultural, inspirado por los movimientos de animación europeos, facilitó el quiebre de la recreación con la matriz fundacional de corte higienista y su distanciamiento del campo de la educación física. La recreación se orientó hacia un enfoque educativo, primero desde los movimientos provenientes del sector no formal y luego en las propias instituciones de enseñanza escolarizada. Esto fue posible gracias a la permeabilidad de los sectores formal y no formal, dado que los recursos humanos son muchas veces los mismos en uno y otro lado.

El rol desempeñado por algunas organizaciones que hacen de la recreación una alternativa para atender las consecuencias de la crisis económica y social, y luego una herramienta de educación crítica y complementaria de la enseñanza escolarizada, fue fundamental para su configuración como campo académico y profesional. Hoy en Uruguay la recreación organizada está presente en diversidad de ámbitos, donde actúan roles profesionales variados y con múltiples abordajes. Especialmente en el caso de la recreación juvenil, muchas organizaciones, como los Scouts, movimientos de las iglesias católicas y protestantes, colegios confesionales y laicos, y diversas organizaciones de la 
sociedad civil, junto con diversas instituciones del Estado, apuestan a la recreación como una estrategia educativa que fortalece la convivencia y la integración social.

Reconocer la especificidad de este enfoque hace a la lógica de un campo en construcción, que se ha ido independizando de la educación física y está buscando su propia identidad. Creemos que la revisión de este proceso, tal como se concretó en Uruguay, aporta pistas para comprender el desarrollo de un enfoque regional de la recreación acorde a los procesos y realidades del sur de América, y da pistas para abordar estrategias de educación e integración social propias e innovadoras.

\section{Referencias bibliográficas}

Dogliotti, P. (2012). Cuerpo y currículum: Discursividades en torno a la formación de docentes de educación física en Uruguay (1874-1948) (Tesis de maestría). Recuperado de http:// posgrados.cse.edu.uy/ sites/ posgrados.cse.edu.uy/ files/ tesis paola_dogliotti.pdf.

Dumazadier, J. (1964). ¿Hacia una civilización del ocio? Barcelona: Estela.

Editorial. (1975). El Heraldo Scout, Boletín de la ASCU, 1(2), 11.

Gomensoro, A. (1954). Fundamentación filosófica de la reeducación juvenil. En R. Ares Pons (org.), Problemas de la juventud uruguaya (pp. 111-141). Montevideo: Marcha. Gomensoro, A. (junio, 2004). Una experiencia educativa de más de 20 años. En Los orígenes de la recreación en el Uruguay. Ponencia presentada en la mesa redonda organizada por el Foro Permanente de Tiempo Libre y Recreación, Montevideo.

Lema, R. (1999). Recreación, tiempo libre y educación en el Uruguay. Revista Prisma, 11, 136-142.

Lema, R. (2016a). Las instituciones de educación formal de Montevideo como espacios de recreación para la construcción de autonomía. En R. Lema y M. J. Monteagudo (eds.), Espacios de ocio y recreación para la construcción de ciudadanía (pp.115138). Bilbao: Universidad de Deusto.

Lema, R. (2016b). La formación de animadores y líderes juveniles en instituciones educativas de Montevideo. Revista Lúdica Pedagógica, 1(23), 53-62.

Lema, R. (2017). Del disciplinamiento de los cuerpos a la humanización del tiempo libre: Prácticas de recreación organizada en Uruguay durante la primera mitad del s.XX. Recorde: Revista de Historia do Esporte, 10(2), 1-32.

Nahum, B., Frega, A., Maronna, M. y Trochon, Y. (1997). El fin del Uruguay liberal (19581973). Montevideo: Ediciones de la Banda Oriental.

Noticias. (1962). El Heraldo Scout, Boletín de la ASCU, 1(1), 8.

Waichman, P. (2004). Tiempo libre y educación: Un desafío pedagógico. Buenos Aires: PW. 